\title{
DEVELOPMENTAL CHARACTERISTICS OF TEMPORAL SHARP TRANSIENTS IN THE EEG OF NORMAL PRETERM AND TERM NEWBORNS
}

\author{
Magda Lahorgue Nunes', Fernando T. Gameleira², \\ Andréa J. Oliveira ${ }^{3}$, Jaderson Costa da Costa ${ }^{4}$
}

\begin{abstract}
Objective: To describe developmental characteristics, morphological aspects and incidence of temporal sharp transients (TST) in normal preterm and term newborns at matched conceptional ages (CA). Method: Neonatal EEGs from two groups of normal newborns were evaluated in order to identify and characterize TST. Group I $(n=40)$ consisted of newborns from 34 to 40 weeks of gestational age (GA) that were submitted to a single EEG between 24 and 48 hours of life. Group II consisted of 10 preterm newborns with GA between 30-32 weeks, followed with a weekly EEG until they reached term. Morphology of TST was divided in 3 groups (temporal sawtooth, isolated transients or repetitive transients). TST index, density and total number were calculated in each polysomnography and related to sleep stages and CA. Laterality (right/ left) was also evaluated. The groups were compared at 34, 36, 38 and 40 weeks of CA. Results: TST index and density decreased with the increase of CA in both groups $(p<0.0001)$. The temporal sawtooth feature was registered in both groups only at 34 weeks. Although rare, repetitive and isolated TST were the most prevalent morphology between 36 - 40 weeks CA. Significant intragroup difference was observed in the comparison of TST density in REM and transitional sleep in GI. Moreover, isolated TST morphology was significant higher in $\mathrm{Gl}$ at 34 weeks when compared to the others CA. No intragroup differences were observed on Gll. No significant differences between the groups were observed considering TST number, index, density, morphology or laterality, at the matched CA. Conclusion: TST are normal features of neonatal EEG, as they are registered in normal newborns. Its incidence varies accordingly to morphology and they tend to disappear following the increase of CA. Temporal sawtooth appears more often in preterm newborns. Our results suggest that TST index, density and morphology variability may be a function of CA.
\end{abstract}

KEY WORDS: neonatal EEG, temporal sharp waves, preterm newborn, sleep ontogenesis.

\section{Características das ondas agudas temporais no EEG de recém-nascidos normais pré-termo e a termo}

RESUMO - Objetivo: Descrever as características, aspectos morfológicos e incidência das ondas agudas temporais (OAT) em recém - nascido pré-termo e a termo pareados por idade concepcional (IC). Método: OAT foram identificadas e analisadas nos EEGs de dois grupos de recém - nascidos normais. $O \mathrm{Gl}(\mathrm{n}=40)$ foi constituído de recém - nascidos com idade gestacional (IG) de 34 a 40 semanas, submetidos a EEG com 24-48 horas de vida. O GIl consistia de 10 recém - nascidos pré - termo com IG entre 30 - 32 semanas, seguidos com EEG semanal até atingirem IC de 42 semanas. As OAT foram divididas de acordo com sua morfologia em serrilhada, isolada e repetitivas. $O$ número total, índice e densidade de OAT foram calculados em cada EEG neonatal e relacionados ao estágio do sono e IC. A lateralidade (esquerda/direita) também foi analisada. Os grupos foram comparados nas seguintes semanas de IC: 34, 36,38 e 40 semanas. Resultados: 0 índice e a densidade de OAT diminuíram com o aumento da IC $(p<0.001)$. A morfologia serrilhada foi registrada em ambos os grupos somente até a IC de 34 semanas. As OAT com morfologia isolada e repetitiva foram visualizadas mais freqüentemente entre 36-40 semanas. No GI foram observadas diferenças significativas em relação à morfologia e densidade de OAT em sono REM, em associação ao aumento da IC. A densidade das OAT isoladas foi significativamente superior no GI na $34^{a}$ semana de IC. Não foram observadas diferenças no GII, assim como também não foi observada diferença significativa entre os recém - nascidos dos grupos I e II quando pareados por IC. Conclusão: OAT são elementos normais do EEG neonatal já que são registradas em recém - nascidos

\footnotetext{
Serviço de Neurologia do Hospital São Lucas (HSL) e Faculdade de Medicina (FAMED) da Pontifícia Universidade Católica do Rio Grande do Sul Porto Alegre RS, Brasil (PUCRS): ${ }^{1}$ Professora Adjunta de Neurologia e Pediatria da FAMED - PUCRS; ${ }^{2}$ Neurologista e Neurofisiologista Clínico, Ex - aluno do Curso de Especialização em Neurociências/ EEG Neonatal do Serviço de Neurologia do HSL - PUCRS; ${ }^{3}$ Neurofisiologista Clínica, Ex - aluna do Curso de Especialização em Neurociências/ EEG Neonatal do Serviço de Neurologia do HSL - PUCRS; ${ }^{4}$ Professor Titular de Neurologia, FAMED - PUCRS
}

Received 11 October 2002, received in final form 30 January 2003. Accepted 19 February 2003.

Dra. Magda Lahorgue Nunes - Serviço de Neurologia, São Lucas Hospital - Av. Ipiranga 6690 sala 220 - 90610-000 Porto Alegre RS Brasil. FAX: 51 333-94936. E-mail: nunes@pucrs.br 
normais. Sua incidência varia de acordo com a morfologia e tende a desaparecer com o aumento da idade concepcional. A morfologia serrilhada é mais freqüente em prematuros. Nossos resultados sugerem que o índice, a densidade e a morfologia das OAT variam de acordo com a idade concepcional.

PALAVRAS-CHAVE: EEG neonatal, ondas agudas temporais, prematuro, ontogênese do sono.

Sharp fast transients are generally normal features in newborn EEG and tend to occur more over frontal and temporal derivations. Temporal sharp transients (TST) usually occur in young preterm neonates and they become more prominent and frequent between $30-32$ weeks of conceptional age $(C A)^{1,2}$. Since the first systematic descriptions of neonatal EEG, the record of TST has been considered a representative pattern of prematurity ${ }^{3}$. These transients have been previously called temporal sawtooth, temporal theta bursts and premature temporal theta ${ }^{4,5,6}$. It has been reported that the number and duration of TST increases until 31 weeks of CA and they tend to disappear until 34 weeks. They usually are recorded bilaterally, but asynchronously, and are more evident during REM sleep ${ }^{7}$.

Different types of TST have been reported in preterm and term newborns, with variable morphology, besides temporal sawtooth ${ }^{8}$. In a previous study we have evaluated the presence of TST and a possible correlation to CA, and we concluded that the presence of TST suggests a preterm newborn EEG ${ }^{9}$. Although related to preterm, TST were also observed in EEGs from close to term newborns. Hughes ${ }^{6}$ reported TST until 39 weeks of CA, with a peak of unilateral TST at 36 weeks of CA.

In previous studies in the literature the morphology of TST, besides the temporal sawtooth pattern, has not been systematically analyzed. Based on the hypothesis that morphological features and incidence of TST varies according to CA, this study was designed to evaluate the morphological variability of TST and if its rate of occurrence can be influenced by the extrauterine development in preterm newborns.

\section{METHOD}

\section{Patient selection}

We report the data of 50 neurologically normal newborns from the São Lucas Hospital - PUCRS School of Medicine, Porto Alegre, Brazil. The newborns were divided into two groups. Group I consisted of 40 preterm and term newborns with gestational age (GA) of 34 weeks $(n=4), 36$ weeks $(n=8), 38$ weeks $(n=14), 40$ weeks $(n=14)$, submitted to one EEG between $24-48$ hours after birth. Group II consisted of 10 preterm newborns with GA between 30 and 32 weeks, who were followed up with a weekly EEG, until they reached 42 weeks CA. Newborns that met the following criteria were sequentially included in the study: admitted to NICU because of preterm or born in our hospital; 5 minutes Apgar score greater than 7; GA calculated by the neonatologist using the Capurro method $^{10}$; adequate weight for GA; normal clinical examination; no evidence of CNS disorder; adequate prenatal maternal care during gestation. The preterm newborns were submitted to at least one cranial ultrasound in the first two weeks of life, and after hospital discharge were followed in the Neonatal Outpatient Follow - Up Clinic at the same Institution. Conceptional age was calculated as adding the number of days since birth to gestational age.

All parents gave informed consent to have their newborns included in the study.

\section{Polysomnographic recordings}

The recordings were performed on a 16 channel EEG and consisted of 10 channels of EEG, electro-oculogram, submental electromyogram, nasal and abdominal respiratory monitoring and electrocardiogram ${ }^{9,11}$. Bipolar montage was used, with double distance electrodes, placed based on the 10-20 system as modified for newborns ${ }^{12,13}$. The state of the newborn and all the movements during the exam were recorded by the technician. All studies were performed in the morning, after the babies were fed, cleaned and dried. The babies were in the supine position and each exam lasted at least 50 minutes or until a complete sleep cycle ( REM - NREM - REM) was recorded ${ }^{1}$.

Other aspects of the EEG data from some of these newborns have been reported elsewhere ${ }^{9,11}$.

\section{Morphology and quantification of TST}

TST were identified in the EEG and divided according to morphology in : temporal sawtooth, isolated transients or repetitive transients.

Temporal sawtooth - brief bursts of four to six sharp or sharp contoured, rhythmic waves at 4-7 Hz, with amplitude between 150 and $250 \mu \mathrm{V}$, in the temporal regions ${ }^{8}$ (Fig 1a).

Isolated transients - single monophasic or diphasic transients, with maximal expression at temporal region, amplitude 50-250 $\mu \mathrm{V}$ (Fig 1b).

Repetitive transients - burst of 2 or more sharp contoured or comb-like rhythmic transients, separated by an interval inferior to 2 seconds, amplitude $<100 \mu \mathrm{V}$ (Fig 1c).

Positive temporal sharp transients were not included in this analyses.

The total number of TST during each exam was calculated regarding morphology, laterality and synchrony, and was related to $C A$.

We calculated a TST index (number of events/ total sleep time $X 60$ ), extrapolated to 60 minutes, to adjust 


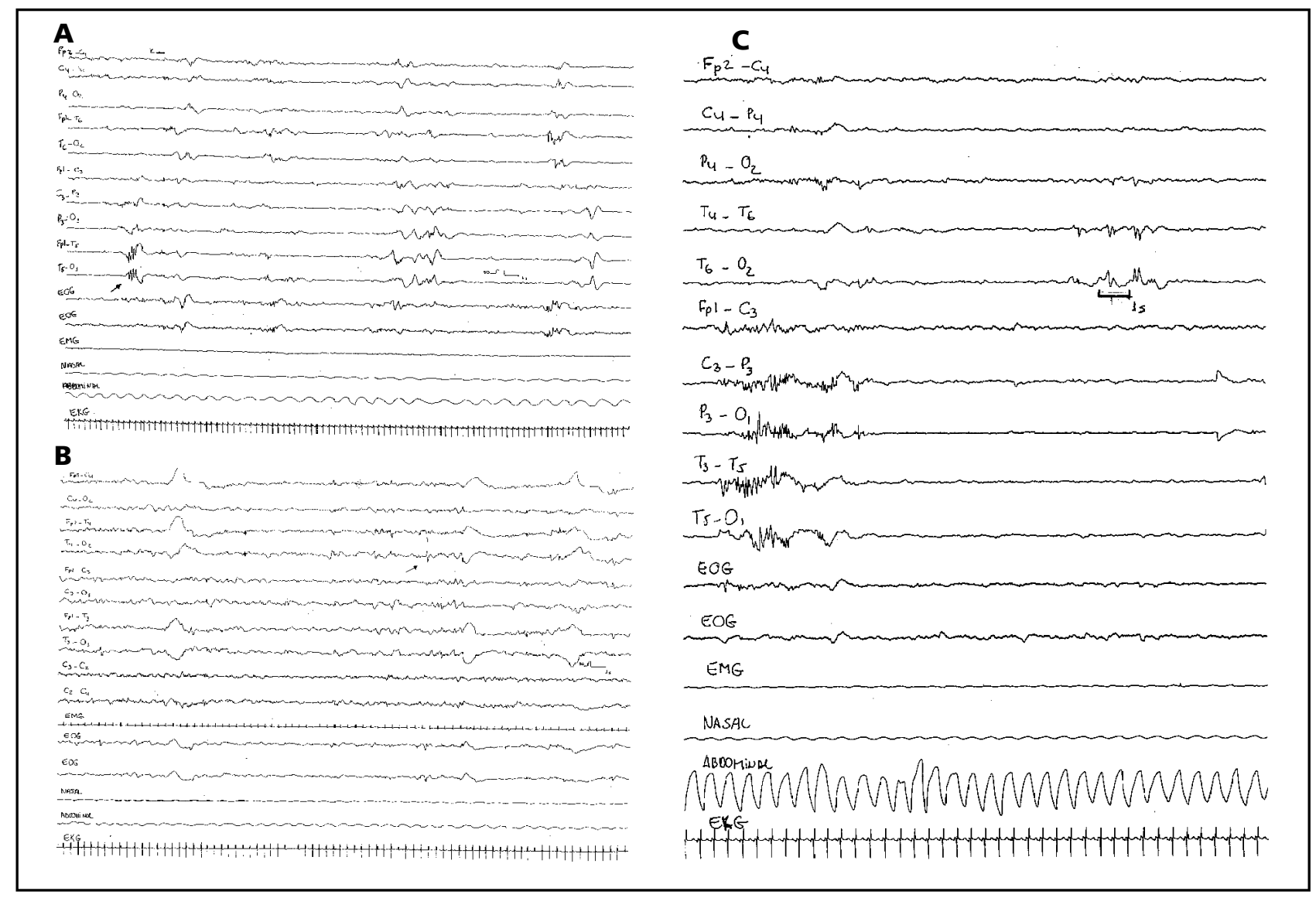

Fig 1. Examples of the different morphologycal features of TST, all EEGs were recorded with speed 15mm/s. In a) example of temporal sawtooth in transitional sleep (NREM - REM) registered at T5 in a newborn with CA $=34$ weeks, b) an isolated TST registered in NREM sleep at T4-O2 in a 38 weeks CA newborn, c) example of the repetitive morphological feature registered at T6, in NREM sleep in a 34 weeks CA newborn.

eventual differences related to different total sleep time in each EEG. TST density was calculated and related to sleep stages (TST number / minutes in each sleep stage).

To determine laterality, TST were counted as they were registered either in left or right side.

The age-related changes in TST index, laterality and morphology were evaluated, and groups were matched at ages $34,36,38$ and 40 weeks. The results were compared considering inter and intra group variability using paired

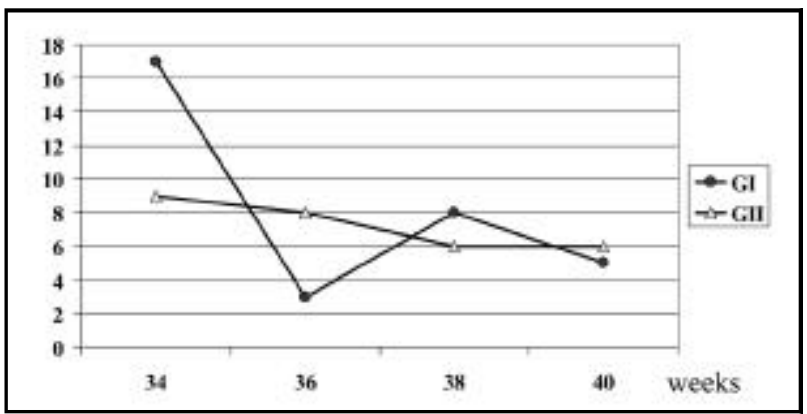

Fig 2. The total number of TST decreased as a function of CA in both groups $(p<0,001)$. and unpaired t Test. We have established as statistically significant, $\mathrm{p}$ values under 0.05 .

\section{RESULTS}

Group I consisted of 5 female and 5 male newborns. Group II consisted of 25 female and 15 male newborns. We have not observed sex differen-

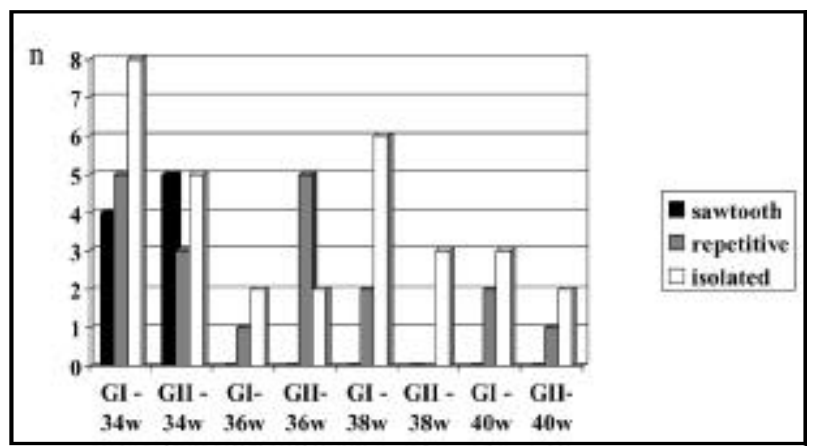

Fig 3. Among the different morphological features of TST suggested in this study the sawtooth pattern was registered only at 34 weeks CA. The isolated morphology predominated on Gl at all ages. 
Table 1. TST index.

\begin{tabular}{lcccc}
\hline CA/Group & $\begin{array}{c}\text { Minimum } \\
\text { Index }\end{array}$ & $\begin{array}{c}\text { Maximum } \\
\text { Index }\end{array}$ & Median & Mean \pm sd \\
\hline $34 w-$ GI & 1.3 & 20.4 & 5.39 & $11.23 \pm 8.65$ \\
$34 w-$ GII & 0 & 9.0 & 1.08 & $2.33 \pm 3.20$ \\
$36 w-$ GI & 0 & 3.42 & 0 & $0.57 \pm 1.21$ \\
$36 w-$ GII & 0 & 5.5 & 0 & $1.53 \pm 2.28$ \\
$38 w-$ GI & 1.6 & 8.8 & 0 & $1.02 \pm 2.37$ \\
$38 w-$ GII & 0 & 4.8 & 0 & $0.81 \pm 1.98$ \\
$40 w-$ GI & 0 & 3.4 & 0 & $0.54 \pm 1.00$ \\
$40 w-$ GII & 0 & 4.2 & 0 & $1.05 \pm 1.77$ \\
\hline
\end{tabular}

OBS: TST index (total number of TST / total sleep time X 60 ).

Table 2. TST density related to sleep stage (mean $\pm s d$ ).

\begin{tabular}{lccc}
\hline CA/Group & REM sleep & NREM sleep & Transitional sleep \\
\hline $34 \mathrm{w}-\mathrm{Gl}$ & $0.8 \pm 0.03$ & $0.2 \pm 0.36$ & $0.4 \pm 0.49$ \\
$34 \mathrm{w}-\mathrm{GII}$ & $0.01 \pm 0.03$ & $0.9 \pm 0.13$ & 0 \\
$36 \mathrm{w}-\mathrm{Gl}$ & $0.006 \pm 0.01$ & $0.003 \pm 0.08$ & 0 \\
$36 \mathrm{w}-\mathrm{GII}$ & $0.01 \pm 0.03$ & $0.02 \pm 0.05$ & $0.15 \pm 0.44$ \\
$38 \mathrm{w}-\mathrm{Gl}$ & $0.04 \pm 0.14$ & 0 & $0.005 \pm 0.02$ \\
$38 \mathrm{w}-\mathrm{GII}$ & 0 & $0,05 \pm 0.12$ & 0 \\
$40 \mathrm{w}-\mathrm{Gl}$ & $0.01 \pm 0.02$ & $0.007 \pm 0.02$ & $0.001 \pm 0$ \\
$40 \mathrm{w}-\mathrm{GII}$ & $0.03 \pm 0.04$ & 0 & 0 \\
\hline
\end{tabular}

OBS: Density (TST number / minutes in each sleep stage). There was a significant difference among group I, regarding TST density in REM and transitional sleep $(p=0.004)$.

ces in any of the comparisons performed considering TST number, density, morphology or laterality. We have analyzed $40 \mathrm{EEGs}$ from group I newborns (4 for 34 weeks , 8 for 36 weeks, 14 for 38 and 40 weeks (A) and 74 from group II. However, for statistics we have included only $29 \mathrm{EEGs}$ from group II that corresponded to CA 34,36,38,40 weeks.

In Group I (one single EEG per newborn), we have found TST in 14/40 newborns (35\%). Regarding CA, in the preterm newborns, all EEGs for 34 weeks had TST and $25 \%$ of the EEGs from 36 weeks had TST. In the term newborns, $28.5 \%$ of the EEGs from 38 and 40 weeks CA had TST.

In Group II we have found TST in 8/10 preterm newborns (80\%), and in $55.5 \%$ of the EEGs from 34 weeks, $37.5 \%$ of the EEGs from 36 weeks, $16.7 \%$ of the EEGs from 38 weeks and in $33.4 \%$ of the EEGs from 40 weeks.
Number of TST - The total number of TST and TST index have a tendency to decrease in both groups according to CA ( $p<0.001)$, (Fig 2), (Table 1). Comparing both groups, TST index was higher in Group I at 34 and 38 weeks CA. However, differences between the groups were not significant considering the matched CA. TST density calculated in relation to sleep phases, decreased in all sleep stages, in both groups, with the increase of CA. Significant intragroup difference was observed comparing REM and transitional sleep in GI (Table 2). No significant differences were observed between the groups at the matched CA, regarding sleep phases and TST density.

Morphology - The temporal sawtooth pattern was registered only at 34 weeks CA in both groups. Although rare the unique transients registered beyond 34 weeks were repetitive or isolated TST (Fig 3). Isolated TST was significant higher in group I at 
34 weeks when compared to higher CA $(p=0.04)$. However, there was no significant difference between the groups concerning each morphological feature at the matched CA.

Laterality - No specific pattern or predominance was identified in the groups regarding laterality.

\section{DISCUSSION}

TST have been studied by many authors either in normal or high risk newborns ${ }^{6,9,14-17}$.There is a consensus that these transients are normal features of neonatal EEG and are related to preterm newborns, although some authors have described their appearance in term or near term newborns with different morphologies 7,8 .

In our study we observed that the total number of TST have a tendency to decrease in both groups in all sleep stages corresponding with the increase of $C A$, suggesting that these transients varies as a function of CA. This finding corroborates to what has been previously reported by other authors ${ }^{1,6}$. TST peak has been described at lower ages than 31 weeks ${ }^{6,16}$. However as we have not studied newborns below 32 weeks CA we cannot compare our data. In spite of that we have observed a descendent slope on TST index and density after 34 weeks.

Many studies have attempted to correlate EEG maturation patterns to extrauterine and intrauterine development; some authors believe that EEG maturation is a function of $C A$, and is independent of extrauterine life development ${ }^{18-20}$. However, other authors have reported differences in EEG maturation $^{21}$ or behavior, when matching term newborns to preterm newborns at same $C A^{9,22}$.

We have not found significant differences between the groups at the matched CA's studied, when considering TST index, density, morphology or laterality; these findings differed from a previous study from Scher ${ }^{17}$, who had observed different peaks and greater number of TST when comparing preterm infants at term post - conceptional ages. Differences observed in the results could be due to methodological aspects, since we did not included positive transients, as did the authors from the previous study. We decided to exclude positive transients in order to clearly differentiate TST from rolandic or temporal positive waves, that could have a pathological significance $\mathrm{e}^{1,2,23}$.

Regarding laterality, Hughes ${ }^{6,14}$ has described a predominance of TST on the right side after 30 weeks of CA. Although we have observed, also, a predomi- nance of right sided transients in $\mathrm{Gl}$ at 38 and 40 weeks, this finding was not significant, probably due to the reduced number of transients registered on term newborns.

In our study, TST were occasionally registered in term newborns, and the predominant morphological patterns were isolated or repetitive TST. We have not found temporal sawtooth after 34 weeks CA, however, Scher ${ }^{16}$ has described a peak of TST at 39-40 weeks when evaluating physiological sharp transients on healthy fullterm newborns.

Finally, Biagioni ${ }^{15}$ described a relationship between incidence of TST and neurological outcome; this author suggested that a higher incidence of TST over 33-34 weeks CA was associated to mild abnormalities on follow-up. Our study was not designed to follow these infants. Nevertheless, all preterm newborns from Group II, and some of the newborns from Group I were followed in our Neonatal Outpatient Follow Up Clinic, from a period varying from 3 months to 4 years and their neuropsychological development, assessed by the Denver screening test and neurological examination was considered normal ${ }^{24}$.

Our results allow to conclude that TST are normal transients of the neonatal EEG, as they are registered in asymptomatic normal newborns. They are a predominant feature of the preterm EEG and they tend to disappear following increase of CA. The morphological feature temporal sawtooth is more related to preterm, while isolated and repetitive unilateral transients could be registered on preterm and term newborns. TST characteristics in term newborns when matched to preterm newborns at the same CA did not significantly differ. These findings allows us to conclude that TST index, density and morphology varies as a function of CA.

\section{REFERENCES}

1. Lombroso CT. Neonatal electroencephalography. In Niedermeyer E, Lopez Da Silva F. (eds) Electroencephalography: basic principles, clinical applications and related fields, 3. Ed. Baltimore: Urban Schwarzenberg 1993;803-875.

2. Lombroso CT. Neonatal polygraphy in full-term and premature infants: a review of normal and abnormal findings. J Clin Neurophysiol 1985;2:105-155.

3. Dreyfus-Brisac C. The electroencephalogram of the premature infant Wld Neurol 1962;3:5-15.

4. Werner SS, Stockard JE, Bickford RG. Atlas of neonatal electroencephalography. New York: Raven Press, 1977.

5. Torres F, and Anderson C. The normal EEG of the human newborn. J Clin Neurophysiol 1985;2:89-103.

6. Hughes JR, Fino JJ, Hart LA. Premature temporal theta. Electroencephalogr Clin Neurophysiol 1987;67:7-15.

7. Lamblin MD, Andre M, Challamel MJ, et al. Electroencephalographie du nouveau-ne premature et a terme. Aspects maturatifs et glossaire. Neurophysiol Clin 1999;29:123-219.

8. Stockard-Pope JE, Werner SS, Bickford RG, Atlas of Neonatal Electroencephalography, 2nd edn. New York Raven Press:1992. 
9. Nunes ML, Da Costa JC, Moura-Ribeiro MVL. Polysomnographic quantification of bioelectrical maturation in preterm and fullterm newborns at matched conceptional ages. Electroencephalogr Clin Neurophysiol 1997;102:186-191.

10. Capurro H, Konicheki S, Fonseca D, Caldeyro-Barcia R. A simplified method for diagnosis of gestational age in the newborn infant. J Pediatr 1978;93:120-122.

11. Nunes ML, Penela MM, Da Costa JC. Differences in the dynamics of frontal sharp transients in normal and hypoglycemic newborns. Clin Neurophysiol 2000;111:305-310.

12. Anders T, Emde K, Parmelee AH. A manual of standardized terminology, techniques and criteria for scoring of states of sleep and wakefulness in newborn infants. UCLA Brain Information Service, Los Angeles, 1971.

13. Curzi - Dascalova LC, Mirmiran M Manual of methods for recording and analyzing sleep-wakefulness states in preterm and full term infants. INSERM, Paris, 1996.

14. Hughes JR, Kohrman MH. Topographic mapping of the EEG in premature infants and neonates. Clin Electroencephalogr 1989;20:228-234.

15. Biagioni E, Bartalena L, Boldrini A, Cioni G, Giancola S, Ipata AE. Background EEG activity in preterm infants: correlation of outcome with selected maturational features. Electroencephalogr Clin Neurophysiol 1994;91:154-162.

16. Scher MS, Bova JM, Dokianakis SG, Steppe DA. Physiological significance of sharp wave transients on EEG recordings of healthy pre-term and full-term neonates. Electroencephalogr Clin Neurophysiol 1994;90:179-185.

17. Scher MS, Bova JM, Dokianakis SG, Steppe DA. Positive temporal sharp waves on EEG recordings of healthy neonates: a benign pattern of dysmaturity in pre-term infants at post-conceptional term ages. Electroencephalogr Clin Neurophysiol 1994; 90:173-178.

18. Dreyfus-Brisac C, Flescher J, Plassart E. L'electroencéphalogramme: critére d 'age conceptionel du nouveau né à terme et prematuré. Biol Neonat 1962;4:154-173.

19. Borsini W, Lambruschini P, Marcacci G. Lo studio del sonno nel neonato a termine e pretermine com L'EEG -poligrafia. Riv Neurol 1990;60:234-235.

20. Ferrari F, Toricelli A, Giustardi A, et al. Bioelectric brain maturation in fullterm infants and in healthy and pathological preterm infants at term post-menstrual age. Early Hum Dev 1992;28:37-63.

21. Scher MS, Steppe D, Dahl RE, Astana S, Guthrie RD. Comparison of EEG sleep measures in healthy full-term and preterm infants at matched conceptional ages. Sleep 1992;15:442-448.

22. Duffy FH, Als H, Mc Anulty GB. Behavioral and electrophysiological evidence for gestational age effects in healthy preterm and fullterm infants studied two weeks after expected due date. Child Dev 1990;61:1271-1286.

23. Da Costa JC, Lombroso CT. Neurphysiological correlates of neonatal intracranial hemorrahge. Electroencephalogr Clin Neurophysiol 1980;50:183.

24. Frankenburg WK, Dodds J, Archer P, Shapiro H, Bresnick B. The Denver II : a major revision and restandardization of the Denver Developmental Screening test. Pediatrics 1992;89:91-97. 